\title{
XXII. Inquiries into coloured light, by a collation of the experiments and observations made by Sir Isaac Newton on that subject; together with some additional ones
}

\section{Governor Pownall}

To cite this article: Governor Pownall (1802) XXII. Inquiries into coloured light, by a collation of the experiments and observations made by Sir Isaac Newton on that subject; together with some additional ones, Philosophical Magazine Series 1, 12:46, 107-112, DOI: 10.1080/14786440208676036

To link to this article: http://dx.doi.org/10.1080/14786440208676036

$$
\text { 曲 Published online: } 18 \text { May } 2009 .
$$

Submit your article to this journal ¿

\section{山 Article views: 2}

Q View related articles ¿ 


\section{$[107]$}

XXII. Inquiries into Coloured Ligbt, by a Collation of the Experiments and Obfervations made by Sir Ifaac Newton on tbat Subjed; togetber witb fome ádditional ones. By Governor Pownal. L.

\section{[Concluded from p. 49.]}

\section{$\mathrm{T}$}

$\mathrm{HE}$ green prifmatic tint is fuppofed to be homogeneous, becaufe confifting of angles of refrangibility in the yellow and in the blue fo exactly connected in degree at the point where they coalefce, that no prifm nor any fucceftion of prifms have as yet decompofed it. It is, however, in various other inftances decompofed; in the circles of colours arifing from the refractions of light paffing between two lenses, as alfo in the rings of colours exhibited on bubbles of water. In thefe inftances its conftituent parts, which combined form the compound green, emerge as yellow on one fide and blue on the other.

Sir Ifaac Newton, in Obferv. iv. part 1. book 2. marking the order of colours in the circles produced by the refraction of light between two lenses, fays, " the green was very copious and lively, inclining on one fide to blue, on the other to yellow :" and again, in part ii. book 2. p. 202. he fays, " the green exhibited is principally conftituted of original green, but not without a mixture of blue and yellow:" again, iu part i. book 2. p. I9o. he fays, "then after a lively orange followed an intenfe brigbt and copious yellow, which was alfo the beft of all the yellows; this changed firft to a greenifh yellow, then to a greenifh blue; but the green between the yellow and the blue was very little and dilute, feeming rather a greenifb wbile than a green: the blue which fucceeded became very good." In this obfervation made on the rings of colours on bubbles, notice the increafing intenfenefs of the light; alfo fucceffive gradations; alfo the gradual procefs of the compofition of green and of its decompofition, which is given in the next obfervation, p. I89: "After the red fucceeded little or no yellow, but a copious green, which at firf inclined a little to yellow, then became a pretty briik and good willow-green, and afterwards changed to a blueith colour ; but there fucceeded neither blue nor violet." In the firtt inftance, the very little and dilute greenifh white, as well as the willow-green in the fecond, was the dominancy of an intervening white, as will cone out hereafter ; and in both inftances the yellowith green and blueifl green mark the compound, partaking on each fide of the yellow or of the blue, 
blue, as the one or the other predominated in the compo. fition.

But to put this matter out of all doubt, the fact comes out on experiment, that when the gradations of the colour take fuch an arrangement that there is no interfection of the yellow orbicular images with thofe of the blue, and fo no coalefcence of thele colours, there is no green.

Obferv. iv. part i. book ii. p. I74. Sir Ifaac Newton fays, \& the colours reckoned in their order from the centre were, black, blue, white, yellow, red; here the blue, and yellow not interfecting or coalefcing, but feparated by an intervening white, there was no green in this gradation of colours: if they had approached fornewhat near to an interfection of their circles, there might have been, as above, a whitifh, or willow-green bordered with yellowinh and blueilh green. The fame fact is ftated in Obfervation ix.p. 181 : the order of this gradation was, " violet, blue', white, yellow, red." Here again an intervening fpace of white excludes the exiftence of green. The fame fact of an intervening wbite between the yellows and the blues, excluding the green, comes out in fome experiments and obfervations made by G.W. J.* in addition to thofe made by Sir Ifaac Newton, where, in p. 99. he ftates, that " diluted purple and blue.hues appear completing, with the external yellow and red, and an intervening wbite, thefe formations of thefe fringes." I will venture to add, in confirmation of all this, one amongft feveral obfervations which I made on thefe facts. Viewing, through a prifm, the folar light as it came through a fah window, and taking the fpectrum in the line of refraction as it came from above, the following circumftances appeared:The frames of the fafh were dark, and gradations of colours proceeded from them. The gradations of blue on the upper fide; thofe of the red, orange, yellow, from the lower fide. The gradations proceeded from the upper fide in this orderdeep blue, and, in fucceffion, the feveral lighter tints or hues of blue till they vanifhed in the folar light. From the under part they proceeded in this order-deep red, then a brighter, going into orange, and the orange fucceffively brightening into yellow, which melted off into the folar light: no gradations of blue fucceeded either order, becaufe there was no going off of light into fhade when the fpectrum was thus tranfparent to the folar light; and as there was no blue to intermix with the laft yellow, there was no green. In proof that this is the reafon, it may be obferved, that if the light itfelf

* A very ingenious work publifhed by Cadell s 799 . 
through which the fpectrum is viewed, decreafes, in any confiderable degree of its brightnefs, there will come on blueith hues, and a very faint intervening greenifh one. To try this circumftance more decidedly, I threw up the fafh, and made an affiftant hold a broad rule, fo that I might view the fpectrum as it proceeded from the two edges in the fame manner as from the frames of the fath: I then directed my affifant to lower the rule down to the bottom of the window, till the yellow in the under gradations interfected the bottom. The yellow of this pofition not going off into tranfparent light, but into thade, the blue hues appeared in very decided tints through all their gradations; and where blue, fucceeding to the yellow, interfected it, a decided green intervened.

Although no common eye, unpractifed in the ufe and arrangement of colours and their various tints, can difcover in the fpaces of the prifmatic colours called homogeneous, when thrown on an opaque furface, any gradations of tints; yet when thefe colours are viewed by the prifm through an open light fo as to be tranfparent, the gradation of fucceffive tints in each homogeneous fpace becomes evidently obfervable to the moft common eye. The obferver may difcern the fact, that no one of thofe prifmatic colours which are called homogeneous is abfolutely fo, but that, as according to the theorem ftated by Sir Ifaac Newton himfelf, they confift of a fucceffive feries of innumerable circular or orbicular images of the fun; the tints of the commonly called homogeneous colour, red, vary according to the innumerable fucceeding angles of refraction, heightening gradually towards orange, and going gradatim into the orange; and that the orange heightens in the fame gradual fucceffion of tints going into yellow, and the yellow, in like manner, into pure light: alfo that the blues of the other gradation of colours are an indifcriminate fucceffion of tints or hues.

Conformably to what is here ftated of the heightening of the gradations of the colours at one end of the fpectrum into light; of the blues going off, by a like gradation at the other end, into thade or dark; Sir Ifaac Newton (Optics, book i. prop. v. exper. 16. p. $85^{\circ}$ ) ftates, that "s the moft luminous of the prifmatic colours are the orange and the yellow; next the green; and that blue is a faint and dark colour, and the indiro and violet the weakeft and darkeft of all colours."

Now from a more decifive examination of the fact by actual experiment we thall be led to fee demonftrably that thefe apparent hues, which are called blue colours, are not colour, but a mere modification of light going off into thade, a partial and fucceflie deprivation of light. 
In the firft place, it is known by Sir Ifaac Newton's ex periment, (Optics, book ii. part iii. prop. 7. p. 236.) " that blacks are inclined to a blueifh colour may be feen from illuminating white paper by light reflected from black fubftances, for the paper will appear of a bluei/b wobite."

In confidering this obfervation on a fact as made by Sir Ifaac Newton, the method to try the effect of throwing a partial portion of light on a fhade occurred to me. I darkened a room partially, letting in a beam of ligbt of five or fix inches breadth by opening one of the fhutters. I then threw the thade of a ruler, by the intercepted light of a candle, on a heet of paper: I then held this paper, with this made fo formed on it, in the beam of light. The effect of this portion of daylight thus thrown on the chade of the ruler was, that the fhade exhibited a pale but decided blue. As I removed this paper, with this hade of the ruler thus thrown on it, further back from the entrance of the light, but fill in the fame beam, this blue, without the alteration of any one circumftance but a further deprivation of light, became of a ftronger, more decided, deeper blux ; and fo on gradually as I removed this paper and thade ftill further back, making a further deprivation of light of a deeper and deeper but decided blue till it went off into a black. This thade, fuffering this gradual deprivation of light, exhibited all the gradations called blue which are feen in the prifmatic fpectrum. Here, then, the fact ftands afcertained, that blue is the effect of a partial light, and that a gradual deprivation of light gives all the gradations of blue as they go off into dark.

Mountains and hills, and even unelevated land, in the horizon exhibit, by the going off or deprivation of light, blue tints in the moft diftant, though fuch are not the natural tints of thefe objecls; and as thefe objects fuffer more and greater deprivations of light in the evening, or from any other incidental circumftance, thefe hues go through all the, gradations of blue.: This any one may fee every day; and the painter, if he is an artift, knows how to copy this phænomenon in the arrangement of his colouring.

Another circumftance in the landfcape of nature is ftill further to be obferved. As the thade of evening comes on, the blue in the diftant horizon not only becomes deeper, but, when the departing light fkirts the line of the horizon, this blue, without any change in the ftate of the refractions, or of the actual colour of the objects, becomes a ftrong vivid purple. The dark blue of the clouds jut above this dkirting of departing light, changes in like manner. The rays of the reddith-yellow light and thote of this blue coming in coin- 
cidence at the fame time to the eye, caufe that fenfation in the optic nerve.

The $\mathrm{kv}$ alfo, the lefs that clouds and reflecting vapours are mixed with it, abforbs the light, and gives out only this blue hue, which is a reflection deprived in part of light * : the more clear the fky, the deeper the blue: in the higher regions of the atmofphere this blue becomes of a deep hue going off into dark.

This circumftance takes place and prevails in the claroobfcuro of all figures. A true artift knows, that if he would copy the real fact in nature, he muft tint the going off of light not with gray and black but with gradations of blues, and give a faint fuffution of green in the firt going off. Zincke, the famous painter in enamel, underftood and copied this fact: he worked an almoft infenfible green into the blues of the firt going off of his lights.

If one may then affume the fact here grounded on the experiments and obfervations of Sir Ifaac Newton, with addition of fome further ones on the cafe as exifting in nature, that the gradations of blue are mere effects of the privation of light as it finks, into thade or darknets; and then, from the teftimony of the vifual fenfes, which are the only teft in the experiments above related, that the gradations of the red even in the prifmatic fpace, wherein it is fuppofed to be homogeneous, of the orange likewife, and fo of the yellow, are only gradual and fucceffive tints of the one primary colour, red, heightening, by an innumerable and infinite feries of angles of refraction, into a more and more brilliant approximation of pure light, as they purify from the fuffufion of colour which they had received in their combination with folar or terreftrial gafes and vapours; it will, on this affumption thus grounded on facts, ftand demonftrably proved (although I do not venture to announce it but with every diffidence) $t b a t$ tbere are not feven, nor tbree, nor two, but ONLY ONE PRIMARY COLOUR-a compound bafis of all the tints of red, orange, and yellow: that green, as an athual and uncompounded primary colour, bas no exiftence: and tbat the blues are only bues arifing from a partial deprivation of ligbt as it goes off into darkne/s.

That all the phænomena of colours produced by the re-

* This circumfiance, alfo, makes the difference of the blue of diftant parts of the landicape as reflected from valleys and lower parts, or from the higher: the deprivation of hight, by its being ablotbed by the clearer air in the latter cale, gives a defper hlue than that which is reltected from the air hanging over the lower purts. This a true artif, who paints from nature, knows. 
fraction of prifms or of lenses, or by thin plates of air or water between lenses made to approach each other, or by the rings on bubbles, or by reflections or inflections of light, may be explained from the facts contained in the above propofition.

All the experiments, obfervations, and reafoning above, refpect only coloured light. I dare not venture, on theory, to affert any thing as to the exiftence of an elementary, pure, uncoloured, uncompounded white light; yet that fome fuch elementary fubftance exifts, combined with one or more of the principles of our atmofphere, and alfo in combuftible and incombuftible, and perhaps animal and vegetable fubftances, feems to be probable; for it can be feparated from fuch in various operations of nature and art.

However, although light may principally exift, combined with caloric and other fubftances, in a gafeous form, yet it may, and it is very generally admitted, that it does affo exift, independent of caloric, in folid bodies and fluids of various kinds ; and heat, it cannot be denied, exifts fenfibly in both combuftible and incombuftible bodies which exhibit no vifible light. Indeed, that light and heat are two diftinct exifting principles is now finally and demonftrably afćertained and proved by Dr. Herfchel's curious experiments of the fact, thowing that heat as well as light are each liable to different and peculiar refractions, by which they are feparated from each other, and take a feparate and diftinct exiftence in different fpace.

$$
\text { Quod reftat defideratum eft. }
$$

XXIII. Hiftory of Aftronomy for the Year 1801. By
Jenome LaLANDE. $\mathrm{T}$ HE commencement of the I th century was diftinguilhed by an aftronomical event, the difcovery of a planet at Palermo in Sicily, by M. Piazzi, on the $1 \mathrm{ft}$ of January *. It was as finall as a far of the 8th magnitude: he obferved it during forty days. The obfervations he fent me arrived too late for ts to be able to follow it, and we were obliged to calculate its orbit from his own oblervations alone. Burckharit, Olbers, Bode, Piazzi, and Gaufs, have found that to reprefent thefe obfervations it is neceffary to fuppofe that

* I here employ the calendar of all nations, being perfuaded that the French government will foon renounce the new calendar, which is not underftood, and cannot be adopted either by our neighbuurs or by the majority of the French themfelves. - L. 